\title{
Myasthenia Gravis Associated with Diphenylhydantoin Therapy For Epilepsy
}

\author{
JOEL BRUMLIK, ROBERT S. JACOBS
}

SUMMARY $A$ young woman with epilepsy developed myasthenic symptoms while taking diphenylhydantoin. The clinical, electromyographic and pharmacologic findings were consistent with myasthenia gravis. Symptoms of myasthenia ceased on withdrawal of the drug, and recurred on readministration, with little apparent relationship to serum phenytoin levels. This unusual effect is discussed with reference to the known effects of diphenylhydantoin at the neuromyal junction.

RÉSUMÉ: Une jeune fermme épileptique manifestait des symptômes myasthéniques quand on lui administrait du diphenylhydantoin. Les examens cliniques, électromyographiques et pharmacologiques révélèrent une myasthénie grave. Les symptômes myasthéniques disparurent après l'abandon du médicament et réapparurent lors de sa reprise, sans grande relation apparente, cependant, avec les doses de sérum. Cet effet inhabituel est discuté en fonction des effets connus du diphenylhydantoin à la jonction neuromusculaire.

From the Departments of Neurology and Pharmacology and Therapeutics, Loyola University Medical Center, 2160 South First Avenue, Maywood, Illinois 60153 .

Reprint Address: Dr. J. Brumlik, Neurology, Loyola University Medical Center, 2160 South First Avenue, Maywood, Illinois 60153 . U.S.A.

\section{INTRODUCTION}

Since diphenylhydantoin was introduced in the treatment of seizure disorders (Merritt and Putnam, 1938), a host of side-effects have been reported, ranging from gingival hypertrophy to lymphomatous changes in the reticuloendothelial system. Only rarely has diphenylhydantoin been implicated in the production of a myasthenic syndrome or myasthenia gravis. (Regli and Guggenheim, 1965; Norris, et al., 1964). The present case report is one such instance.

\section{CASE REPORT}

A 26 year old white female first consulted us at age 18 because of grand mal seizures which had begun 4 years previously. Her early history was unremarkable; birth had been without difficulty and her childhood passed without serious illness or trauma. When first seen, the neurological examination was within normal limits. She was placed on diphenylhydantoin, $100 \mathrm{mg}$. three times a day. On a few occasions, when she reduced the amount of medication, grand mal convulsions recurred. An EEG at that time (October 22, 1965) showed bilateral synchronous spike-and-wave complexes at $3 /$ second and left midtemporal sharp activity. When she was 23 years old, "momentary staring spells" occurred for the first time, and an EEG (January 13, 1970) again showed spikeand-wave discharges. Mephobarbital, 30 mg. three times a day, was added to the regimen. Seizures remained controlled over the next year, but recurred when medication was reduced.

In July, 1972, she complained of a sore throat and chest pain; another physician saw her and made a diagnosis of "intercostal neuralgia." There had been no rash or other skin manifestations. When seen 2 weeks later, she called attention to drooping of her left eyelid, which, to- gether with occasional double vision, had been present for a few weeks. Examination revealed slight ptosis but no extraocular muscle weakness. Anisocoria, anhydrosis and enophthalmos were not found. Ptosis was reversed by $2 \mathrm{mg}$. edrophonium intravenously; a diagnosis of myasthenia gravis was made, but no anticholinesterase medication advised. Anticonvulsant treatment (mephobarbital $30 \mathrm{mg}$. and diphenylhydantoin $100 \mathrm{mg}$. each three times a day) was continued. One month later she developed dysphagia, fatigue of hand grasp and, within another month, the proximal muscles were objectively weak. Her speech became slurred.

In November, 1972, she was hospitalized at Foster G. McGaw Memorial Hospital at Loyola University Medical Center. Her voice had become nasal and her facial muscles weak. There was minimal weakness of the anterior neck flexors. Laboratory studies revealed SMA-12, normal; $\mathrm{T}_{3}$ resin uptake, $31 \%$ (normal 25-30\%); $\mathrm{T}_{4} \mathrm{M}-\mathrm{P}, 4.6 \mathrm{mg} . \%$ (normal 5-14 mg.\%); $\mathrm{T}_{7}, 1.43$ (normal 1.25-4.9); calcium $9.4 \mathrm{mg} . \%$ (normal 8.5-10.5 mg.\%); phosphorus, $4.75 \mathrm{mg} . \%$ (normal 2.5-4.5 mg.\%); glucose, $80 \mathrm{mg} . \%$ (normal 65-110 mg.\%); alkaline phosphatase, 65 u (normal 30-85 u); LDH, 155 $\mathrm{u}$ (normal 100-250 u); SGOT, $40 \mathrm{u}$ (normal 20-40 u); WBC, 12,700 (74 polymorphonuclear, 2 stab, 17 lymphocytes, 2 monocytes, 5 eosinophiles); LE prepar tions, negative $\times 3$; urine, negative; antinuclear antigens, negative; RPR, negative; chest $x$-ray for thymoma, negative; diphenyldantoin level, $27 \mathrm{\mu g} / \mathrm{ml}$. (therapeutic: $10-20 \mu \mathrm{g} / \mathrm{ml}$ ). EEG showed bilateral spike-and-wave discharges and bitemporal sharp activity. EMG showed $33 \%$ decay at 20 and 30 second stimulation.

A second edrophonium test was performed and again the weakness was reversed. Neostigmine, $22.5 \mathrm{mg}$. every 3 hours allowed her to be sent home, stronger and with no ptosis. Over the next 
month, because of increasing weakness, neostigmine was raised to $30 \mathrm{mg}$. every 3 hours. At that time it was first suspected that diphenylhydantoin might be implicated in the production of the myasthenic syndrome; it was stopped. She remained seizure-free on a regimen of primidone, $100 \mathrm{mg} .3$ times a day, and mephobarbital $64 \mathrm{mg} .4$ times a day. Within 3 months (November 24, 1972 to February 27, 1973) the symptoms of myasthenia gradually diminished and she was able to eliminate neostigmine altogether.

She had an unusual "spell" in late February, 1973, and diphenylhydantoin, 100 mg. 3 times a day, was resumed in place of primidone. Within 2 weeks ptosis returned (Figure 1) together with dysphagia, dysarthria and dysphonia. The proximal shoulder girdle muscles were slightly weak. These symptoms were reversed by $5 \mathrm{mg}$. edrophonium intravenmeq/L. (normal 134-147 meq/L.); potassium 3.9 meq/L. (normal 3.6-5.5 meq/L.); chloride, $101 \mathrm{meq} / \mathrm{L}$. (normal 95-105 ously. Serum sodium at this time was 138

meq/L.); total calcium, $9.0 \mathrm{mg} . \%$; ionized calcium, $3.8 \mathrm{mg} . \%$ (normal); total serum protein, $7.4 \mathrm{gm} . \%$ (normal 6.8-8.6 gm.\%). Serum diphenylhydantoin level was 22 $\mu \mathrm{g} / \mathrm{ml}$. A repetitive stimulation study (EMG) (Figure 2) revealed a $50 \%$ decline of the evoked response recorded from the abductor digiti quinti. This was reversed by the intravenous administration of edrophonium.

She was advised to resume the previous schedule of anticonvulsant and anticholinesterase therapy (mephobarbital, primidone and neostigmine). Twelve days after diphenylhydantoin was discontinued, the serum level of this drug was 37 $\mu \mathrm{g} / \mathrm{ml}$. Although the symptoms of myasthenia persisted there were no cerebellar signs, such as nystagmus. Three months later diphenylhydantoin was undectable in her serum. Four months later she was first able to reduce the amount of prostigmine because of gradual improvement of the symptoms of myasthenia. By five months she was asymp-

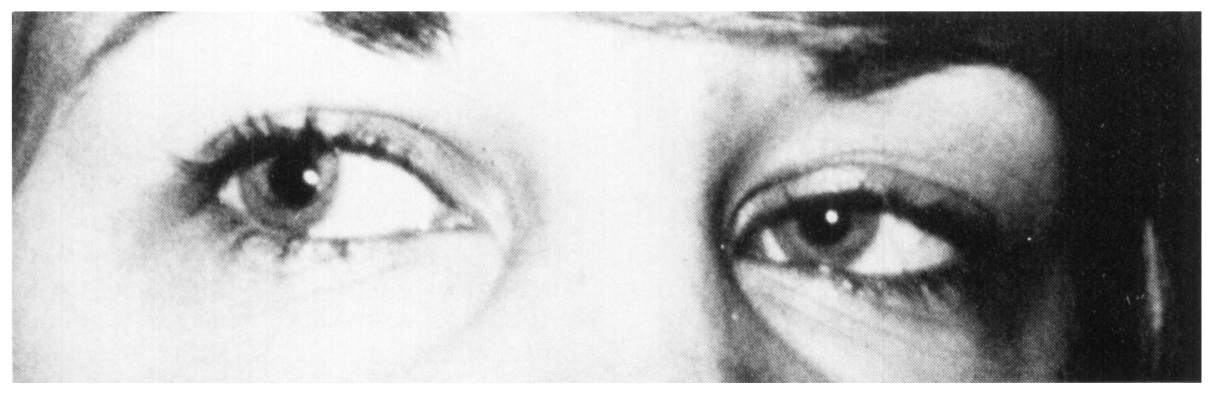

Figure 1. Ptosis of left eyelid in February 1973.

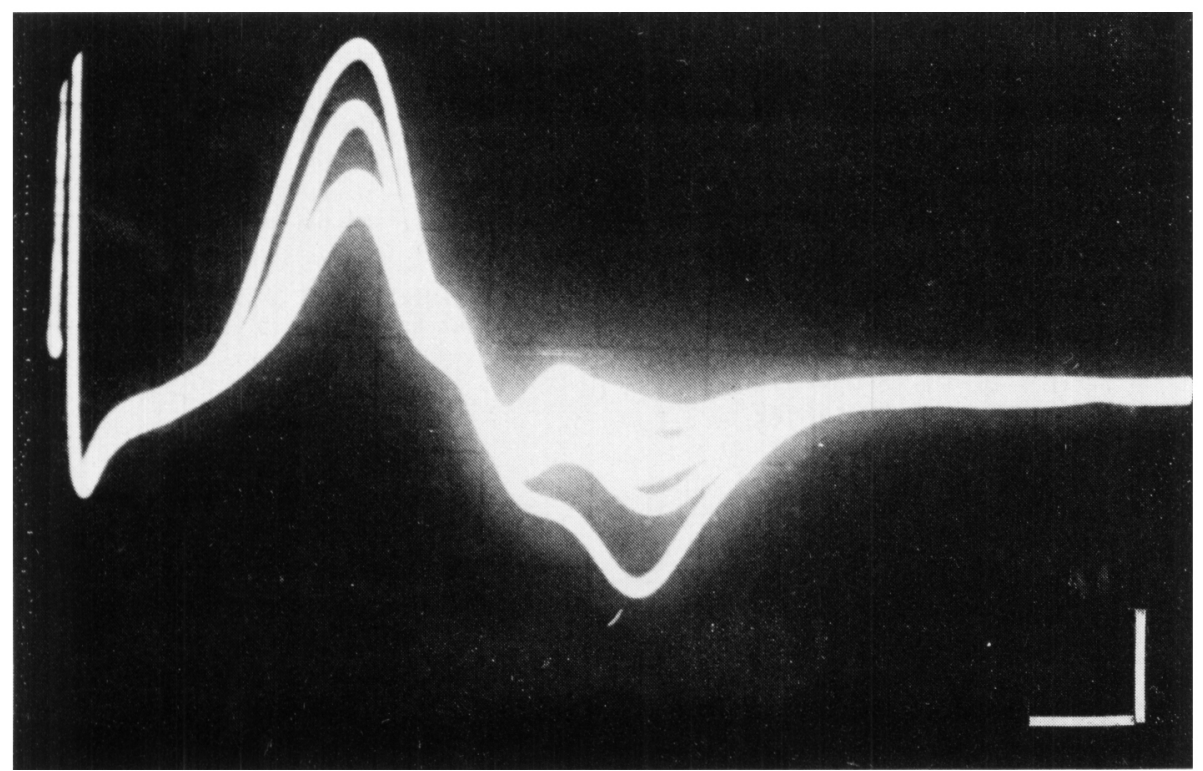

Figure 2. Repetitive stimulation while on diphenylhydantoin. Repetitive stimulation of the left ulnar nerve with $10 / \mathrm{sec}$. stimuli, recording from the hypothenar eminence using surface electrodes. $50 \%$ decline of the evoked response. Calibration: $2 \mathrm{mV}, 2$ msec. tomatic and anticholinesterase medication had been discontinued.

\section{DISCUSSION}

Norris, et al., (1964) reported two cases of myasthenic syndrome associated with the administration of diphenylhydantoin for epilepsy and one following ingestion of the drug in a suicide attempt. Myasthenic fatigue was recorded during repetitive stimulation, but since edrophonium was not administered there was no conclusive proof of myasthenia gravis. Further, the first case was complicated by pernicious anemia; termination of diphenylhydantoin coincided with the administration of vitamin $\mathrm{B}_{12}$. One case had clinical signs of diphenylhydantoin intoxication (ataxia, nystagmus, etc.) at which time serum diphenylhydantoin level was $10 \mu \mathrm{g} / \mathrm{ml}$.

In the report of Regli and Guggenheim (1965), 6 years after mephenytoin was started for a seizure disorder, a 24 year old female developed ptosis and bulbar fatigue. The limbs were unaffected. Repetitive stimulation (EMG) revealed significant decline of the evoked response which could be reversed by intravenous edrophonium. However, oral pyridostigmine seemed to have no effect. Within 2-3 weeks after pyridostigmine was stopped, the symptoms of myasthenia disappeared, and she was asymptomatic without anticholinesterase medication. Serum levels of phenytoin were not reported.

The present case is similar to that of Regli and Guggenheim. Of interest is the recurrence of weakness when diphenylhydantoin was restarted, and the definite clinical response to anticholinesterase medication. The latter suggests that the neuromuscular block may be clinically related to myasthenia gravis. Initially serum levels of diphenylhydantoin were slightly over therapeutic range, but there were no clinical signs of intoxication. This implies that the neuromyal effect produced by diphenylhydantoin which persisted long after the drug had been discontinued the second time suggests abnormal metabolism of the drug by the 
liver and/or abnormal storage and elimination. Why there were no cerebellar or other central nervous system signs with such a level of medication is unknown.

Little investigative work has been done to clarify the effect of diphenylhydantoin on the neuromuscular synapse. Toivakka and Hokkanan (1969) found EMG evidence of myasthenic fatigue in 4 out of 8 patients taking the drug for epilepsy, none of whom had clinical symptoms of myasthenia gravis. Raines and Standaert (1966) reported that diphenylhydantoin abolishes repetitive neural afterdischarges from the cat nerve terminal. Post-tetanic stimulation was markedly reduced. Woodbury (1955) measured sodium turnover in rat brain, heart and skeletal muscle. Increased sodium ion turnover from the cell could theoretically lead to decreased muscle membrane excitability. Norris, et al., (1964) carried out in situ experiments utilizing the rat anterior tibialis and peroneus longus muscles. Intravenous administration 10-15 $\mathrm{mg} . / \mathrm{kg}$. diphenylhydantoin intensified the neuromuscular fatigue which developed during rapid repetitive stimulation. It was reversed by intravenous edrophonium. The neuromuscular fatigue caused by diphenylhydantoin was not evident when the preparation was stimulated directly. These investigators also noted that diphenylhydantoin potentiated the duration of neuromuscular block produced by d-tubocurarine and decamethonium. The decamethonium response was biphasic, in that diphenylhydantoin transiently antagonized decamethonium and then intensified its action. The site and mechanism of action of diphenylhydantoin on neuromuscular transmission has not, as yet, been defined further.

Trimethadione, another anticonvulsant agent, has also been reported to be associated with a myasthenia gravis-like syndrome (Peterson, 1966). The symptoms remitted four and one-half months after withdrawal of the drug. Anti-nuclear, antithymic and anti-muscle antibodies were pre- sent during the period of weakness, but not after cessation of medication. In a second, similar case, Booker, et al., (1970) stated that complete remission of myasthenic symptoms might require 6 months. In this case, too, auto-antibodies were present. The effect of diphenylhydantoin on the latter has yet to be clarified. Since both trimethadione and diphenylhydantoin are anticonvulsant drugs, and since both have been reported to be associated with myasthenia gravis, it would be logical to seek some common denominator of structure and/or pharmacologic action. Trimethadione is a methylated derivative of the hydantoin nucleus common to both it and diphenylhydantoin. One might speculate that this hydantoin nucleus or a metabolite thereof might be the offending agent in the production of a myasthenic syndrome. Antigen-antibody reactions to drugs have been demonstrated as a factor in a variety of hypersensitivity or allergic reactions. The drug or one of its metabolites may combine with a protein to form complexes that are highly antigenic and subsequently induce formation of antibodies. Clinical manifestations of these reactions include skin (dematitis, erythema multiforme, anaphylaxis, urticarial reactions) and occasionally neurologic manifestations. In this regard, diphenylhydantoin has occasionally been associated with periarteritis nodosa and lupus erythematosus. It is conceivable that an atypical antibody formed to diphenylhydantoin may also interfere with normal neuromuscular transmission. The delayed onset of myasthenic symptoms, delayed excretion of the drug and slow recovery are consistent with such an interpretation.

It is still unclear whether this rare myasthenic effect of diphenylhydantoin is a direct consequence of the drug itself, or whether a "subclinical" or "latent" myasthenia is made manifest. The response of our case to anticholinesterase medication suggests a close similarity, if not identity, of the symptoms with myasthenia gravis, and the disappearance of the symptoms with cessation of medication implies a true drug-effect, rather than mere chance association. Such "drug-induced" myasthenia gravis also implies that the latter may represent a syndrome of diverse etiology rather than a disease entity sui generis.

\section{REFERENCES}

BOOKER, H. E., CHUN, R. W. M., SANGNINO, M. (1970). Myasthenia gravis syndrome associated with trimethadione. Journal American Medical Association, 212, 2260-2263.

HOEFER, P. D., ARONAR, H., ROWLAND, L. P. (1958). Myasthenia gravis and epilepsy. Archives of Neurology and Psychiatry, 80, 10-17.

LASCELLES, P. T., KOCEN, R. S. and REYNOLDS, E. H. (1970). The distribution of plasma phenytoin levels in epileptic patients. Journal of Neurology, Neurosurgery and Psychiatry, 33, 501-505.

MERRITT, H. H. and PUTNAM, T. J. (1938). Sodium diphenylhydantoinate in the treatment of convulsive disorders. Journal American Medical Association, 111, 1068-1073.

NORRIS, F. H., COTELLA, J. and MCFARLIN, D. (1964). Effect of diphenylhydantoin on neuromuscular synapses. Neurology, 14, 869-876.

RAINES, A. and ST ANDAERT, F. G. (1966). Pre- and postjunctional effects of diphenylhydantoin at the cat soleus neuromuscular junction. Journal of Pharmacology Experimental Therapeutics, 153, 361-366.

REGLI, F. and GUGGENHEIM, P. (1965). Myasthenisches Syndrom als seltene Komplikation unter Hydantoinbehandlung. Nervenarzt, 36, 315-318.

PETERSON, H. (1966). Association of trimethadione therapy and myasthenia gravis. New England Journal of Medicine, 274, 506-507.

SA, P. C. and FELDMAN, D. S. (1973). Motor nerve terminal and muscle membrane stabilization by diphenylhydantoin administration. Archives of Neurology, 28, 376-379.

TOIVAKKA, E. and HOKKANEN, E. (1969). A neurophysiological study of the subclinical derangement of the neuromuscular transmission in epileptics using diphenylhydantoin. Scandanavian Journal Clinical Laboratory Investigation, 23, Supp., 108, 66.

WOODBURY, D. M. (1955). Effect of diphenylhydantoin on electrolytes and radial sodium turnover in brain and other tissue of normal, hyponatremic and postictal rats. Journal of Pharmacology Experimental Therapeutics, 115, 74-95. 